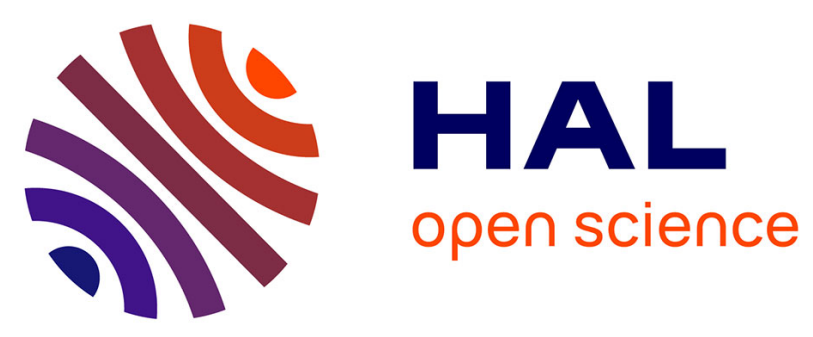

\title{
Management of hypertrophic pylorus stenosis with ultrasound guided single shot epidural anaesthesia - A retrospective analysis of 20 cases
}

Harald Willschke, Anette-Marie Machata, Winfried Rebhandl, Thomas Benkoe, Stephan C Kettner, Lydia Brenner, Peter Marhofer

\section{To cite this version:}

Harald Willschke, Anette-Marie Machata, Winfried Rebhandl, Thomas Benkoe, Stephan C Kettner, et al.. Management of hypertrophic pylorus stenosis with ultrasound guided single shot epidural anaesthesia - A retrospective analysis of 20 cases. Pediatric Anesthesia, 2010, 21 (2), pp.110. 10.1111/j.1460-9592.2010.03452.x . hal-00599904

\section{HAL Id: hal-00599904 https://hal.science/hal-00599904}

Submitted on 11 Jun 2011

HAL is a multi-disciplinary open access archive for the deposit and dissemination of scientific research documents, whether they are published or not. The documents may come from teaching and research institutions in France or abroad, or from public or private research centers.
L'archive ouverte pluridisciplinaire HAL, est destinée au dépôt et à la diffusion de documents scientifiques de niveau recherche, publiés ou non, émanant des établissements d'enseignement et de recherche français ou étrangers, des laboratoires publics ou privés. 


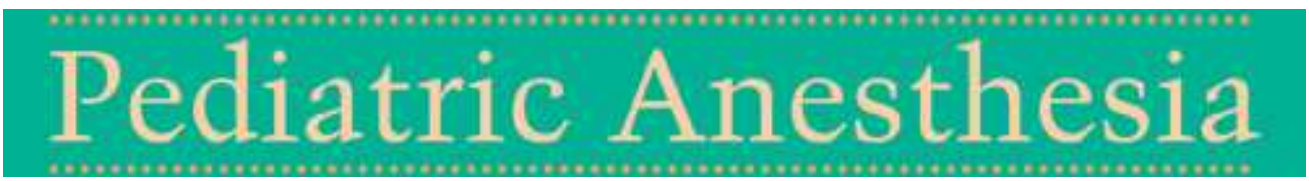

\section{Management of hypertrophic pylorus stenosis with ultrasound guided single shot epidural anaesthesia - A retrospective analysis of 20 cases}

\begin{tabular}{|r|l|}
\hline Journal: & Pediatric Anesthesia \\
\hline Manuscript ID: & PAN-2010-0331.R2 \\
\hline Manuscript Type: & Original Paper \\
\hline Date Submitted by the & $20-$ Sep-2010 \\
\hline Complete List of Authors: & $\begin{array}{l}\text { Willschke, Harald; Medical University of Vienna, Anaesthesia, } \\
\text { Intensive Care Medicine and Pain Therapy } \\
\text { Machata, Anette-Marie; Medical University of Vienna, Department of } \\
\text { Anaesthesia, General Intensive Care and Pain Therapy } \\
\text { Rebhand, Winfried; Medical University of Vienna, Paediatric } \\
\text { Surgery } \\
\text { Benkoe, Thomas; Medical University of Vienna, Paediatric Surgery } \\
\text { Kettner, Stephan; Medical University of Vienna, Anaesthesia, } \\
\text { Intensive Care Medicine and Pain Therapy } \\
\text { Brenner, Lydia; Medical University of Vienna, Anaesthesia, } \\
\text { Intensive Care Medicine and Pain Therapy } \\
\text { Marhofer, Peter; Medical University of Vienna, Anaesthesia, } \\
\text { Intensive Care Medicine and Pain Therapy }\end{array}$ \\
\hline Key Words: & \begin{tabular}{l} 
regional < Ultrasound, infant < Age, local anesthetics < Drugs \\
\hline
\end{tabular} \\
\hline
\end{tabular}




\title{
Management of hypertrophic pylorus stenosis with ultrasound guided single shot epidural anaesthesia - A retrospective analysis of 20 cases
}

\author{
HARALD WILLSCHKE MD*, ANETTE-MARIE MACHATA MD*, \\ WINFRIED REBHANDL MD**, THOMAS BENKOE MD**, \\ STEPHAN C. KETTNER MD*, LYDIA BRENNER MD* AND PETER MARHOFER MD* \\ *Medical University of Vienna, Department of Anaesthesia, Intensive Care Medicine and \\ Pain Therapy, A-1090 Vienna, Austria \\ **Medical University of Vienna, Department of Surgery, Division of Paediatric Surgery, \\ A-1090 Vienna, Austria \\ Harald Willschke, Anette-Marie Machata, Stephan C. Kettner and Peter Marhofer: Professor \\ of Anaesthesia and Intensive Care Medicine at the Department of Anaesthesia, Intensive Care \\ Medicine and Pain Therapy, Medical University of Vienna \\ Lydia Brenner: Consultant and staff member of the Department of Anaesthesia, Intensive \\ Care Medicine and Pain Therapy, Medical University of Vienna \\ Winfried Rebhandl: Professor of Surgery, Department of Surgery, Division of Paediatric \\ Surgery, Medical University of Vienna \\ Thomas Benkoe: Consultant and staff member of the Department of Surgery, Division of \\ Paediatric Surgery, Medical University of Vienna
}

Short running title:

Epidural anaesthesia for hypertrophic pylorus stenosis

Conflict of interest declared:

None

Address of correspondence:

Peter Marhofer, MD

Professor of Anaesthesia and Intensive Care Medicine

Medical University of Vienna

Department of Anaesthesia, Intensive Care Medicine and Pain Therapy

Waehringer Guertel 18-20

A-1090 Vienna, Austria

+431404004107 (phone)

+431404004028 (fax)

peter.marhofer@meduniwien.ac.at 


\section{Summary}

Aim: To retrospectively describe the performance of ultrasound guided thoracic epidural anaesthesia under sedation for anaesthesia management of open pyloromyotomy.

Background: Anaesthesia management for hypertrophic pylorus stenosis is usually performed under general anaesthesia with tracheal intubation. Only a few publications describe avoidance of tracheal intubation in infants by using spinal or caudal anaesthesia. The present retrospective analysis describes the performance of ultrasound guided thoracic epidural anaesthesia under sedation for anaesthetic management of open pyloromyotomy.

Methods: Twenty consecutive infants scheduled for pyloromyotomy according to the WeberRamstedt technique were retrospectively analysed. After sedation with nalbuphine and propofol, an ultrasound guided single shot thoracic epidural anaesthesia was performed with $0.75 \mathrm{ml} \mathrm{kg}^{-1}$ ropivacaine $0.475 \%$. Insufficient blockade was defined as increase of HR > $15 \%$ from initial value and / or any movements at skin incision. In those cases we were prepared for rapid sequence intubation according to the departmental standard.

Results: All pyloromyotomies could be performed under single shot thoracic epidural anaesthesia and sedation. One case of moderate oxygen desaturation was treated with intermittent ventilation via face mask.

Conclusions: Thoracic epidural anaesthesia under sedation for pyloromyotomy has been a useful technique in this retrospective series of infants suffering from hypertrophic pylorus stenosis. In 1/20 infants short term assisted ventilation via face mask was required. Undisturbed surgery was possible in all cases.

Keywords: Hypertrophic pylorus stenosis; thoracic epidural anaesthesia; ultrasound 


\section{Introduction}

Hypertrophic pyloric stenosis (HPS) is a frequent disease in infants with an incidence of 0.95.1 per 1000 cases (1-4). The main symptoms of HPS are progressively worsening "projectile" vomiting, poor feeding and dehydration caused by a gastric outlet obstruction due to a hypertrophic pylorus. The average age and weight of infants with HPC is 5 weeks and 4 $\mathrm{kg}$, respectively (5).

Anaesthesia management for HPS is usually performed under general anaesthesia with tracheal intubation. Tracheal intubation puts these infants at risk of regurgitation, with the potential of aspiration of gastric contents, and rapid sequence intubation is indicated. Beside the special character of anaesthesia induction in children with HPS, rapid sequence intubation in infants should be always considered as high risk procedure. Despite preoperative correction of acid-base balance and hypovolemia, prolonged mechanical ventilation might be required due to remaining metabolic alkalosis and a subsequent delayed equilibrium of the cerebrospinal fluid with the systemic circulation $(6,7)$.

Only a few publications describe avoidance of tracheal intubation and mechanical ventilation in infants undergoing surgery for treatment of HPS by using spinal $(8,9)$ or caudal anaesthesia $(10,11)$. The major drawback of high spinal anaesthesia is the unpredictable cranial subarachnoidal spread of local anaesthesia with subsequent respiratory failure. Caudal anaesthesia on the other hand might be insufficient for pyloromyotomy with a skin incision above the umbilicus.

Thoracic epidural anaesthesia might be an option for anaesthetic management of HPS. Until today, a lot of practitioners have concerns against thoracic epidural punctures in infants due to safety reasons. Recently our study group has developed a technique to directly observe the spread of local anaesthetic inside the epidural space in neonates and infants by ultrasound (12, 
13). Consequently, we used this technique for single shot thoracic epidural punctures in infants undergoing pyloromyotomy, and analysed the first 20 consecutive cases in a retrospective manner. 


\section{Methods}

We included 20 consecutive infants with HPS in this retrospective analysis. Parent's informed consent included an exact description of the anaesthesia procedure (aspiration of gastric juice via a naso-gastric tube, sedation, ultrasound guided single shot epidural anaesthesia) and possible need for rapid sequence induction. After initial diagnosis of HPS by clinical status, ultrasound and blood gas analysis (BGA), $10 \mathrm{mLkg}^{-1} \mathrm{~h}^{-1}$ Elo-Paed balanced plus glucose $1 \%$ (Fresenius Kabi Inc., Graz, Austria) was administered via a peripheral venous access until a $\mathrm{HCO}_{3}$ of $\leq 28 \mathrm{mmol}^{-1}$ and a BE of $<+2$ was achieved.

\section{Pre-epidural preparation}

The epidural puncture site between the T10 and T11 vertebral levels was prepared with EMLA cream 30 min prior epidural puncture and infants were premedicated with midazolam $1 \mathrm{mg} \mathrm{kg}{ }^{-1}$ via the rectal route. After transfer to the operation room, children were placed on a forced-air warming device (Bair Hugger warming blanket, Arizant Inc., Eden Prairie, MN, USA). Standard monitoring included ECG, $\mathrm{SpO}_{2}$ and non-invasive blood pressure. Sedation was induced with nalbuphine $0.1 \mathrm{mgkg}^{-1}$ and a loading dose of propofol $1.0-2.0 \mathrm{mg} \mathrm{kg}^{-1}$, administered over 30 seconds. If necessary, supplemental doses of propofol $0.5 \mathrm{mg} \mathrm{kg}^{-1}$ were administered until adequate sedation was achieved. Sedation was considered adequate, when the patient slept, arousable only with significant physical stimulation. This type of sedation was previously published by Machata et al. and Brenner et al. in 500 and 512 cases, respectively $(14,15)$.

Gentle aspiration of gastric juice via a naso-gastric tube was performed before initiation of the sedation procedure. The maintenance of spontaneous respiration was continuously verified by an end-tidal $\mathrm{CO}_{2}$ line placed inside a face mask. Via this face mask oxygen / air $\left(\mathrm{FiO}_{2} 50 \%\right)$ was administered. Infants received $10 \mathrm{mLkg}^{-1} \cdot \mathrm{h}^{-1}$ Elo-Paed balanced plus glucose $1 \%$. 


\section{Epidural puncture}

The single shot epidural anaesthesia was performed under sterile conditions in left lateral position between the T10 and T11 vertebral spaces. The neuraxial structures were directly visualized with a sterile covered $38 \mathrm{~mm} \mathrm{13-6} \mathrm{MHz} \mathrm{linear} \mathrm{ultrasound} \mathrm{probe} \mathrm{and} \mathrm{a} \mathrm{transportable}$ ultrasound machine (M-Turbo, SonoSite Inc., Bothell, WA, USA) from paramedian. Once the dura mater and the epidural space were identified, the puncture was performed with a 20G, 50 mm Tuohy needle and an $8 \mathrm{ml}$ loss-of-resistance (LOR) syringe (BBraun Inc., Melsungen, Germany) via a median approach (Figure 1) using ropivacaine $0.475 \%$. A total volume of $0.75 \mathrm{ml} \mathrm{kg}^{-1}$ ropivacaine $0.475 \%\left(=3.56 \mathrm{mg} \mathrm{kg}{ }^{-1}\right)$ was administered under ultrasound observation of the spread of local anaesthetic (Figure 2). After performance of the epidural blockade the children were turned in supine position.

\section{Surgical procedure}

Fifteen minutes after performance of the block, skin incision was performed via a right lateral horizontal approach, according to the Weber-Ramstedt technique (16). After pyloromyotomy, saline was administered in the surgical wound, and a moderate volume of air was insufflated via the gastric tube to exclude accidental perforation of the pylorus.

\section{Emergency management}

All equipment for advanced airway management was prepared in cases of respiratory failure. Respiratory failure was defined as the development of paradox ventilation, disappearance of end-tidal $\mathrm{CO}_{2}$ curve and / or decrease in $\mathrm{SpO}_{2}<92 \%$. The following sequential airway management was initiated to re-establish adequate oxygenation: 
- careful ventilation via face mask with inspiratory pressure $<10 \mathrm{mmHg}$

- rapid sequence intubation according to the departmental standard (propofol $8.0 \mathrm{mg} . \mathrm{kg}$ ${ }^{1}$, rocuronium $\left.0.6 \mathrm{mg}^{\mathrm{kg}}{ }^{-1}\right)$.

Definitions for bradycardia and hypotension were a decrease in heart rate and MAP $>25 \%$ from initial values and treated with atropine $0.01 \mathrm{mg} \mathrm{kg}{ }^{-1}$ and a fluid bolus of $10 \mathrm{ml} \mathrm{kg}^{-1}$, respectively.

Insufficient blockade was defined as increase of HR $>15 \%$ from initial value and / or any movements at skin incision. In those cases we were prepared for rapid sequence intubation according to the departmental standard.

\section{Postoperative management}

After transfer to the recovery room, pain status of the children was monitored via OPS score, in which objective behavioural variables (crying, facial expression, position of torso and legs, motor restlessness) are assessed. Each pain variable is scored on a three-point scale $(0=$ none, $1=$ moderate, $2=$ severe) to give a maximum cumulative score of 10 . The scores were evaluated after admission in the recovery room and every 30 min during the first 2 postoperative hours. If the OPS score was $\geq 6$ in two subsequent measurements, the child received acetaminophen $40 \mathrm{mg} \mathrm{kg}^{-1}$ rectally. Due to the retrospective nature of this study no OPS scores could be evaluated on the ward.

Postoperative nutrition was performed by ad libitum feeding (17). The epidural puncture site was examined $24 \mathrm{~h}$ postoperatively to detect local infection, according to the departmental standard. 


\section{Results}

We analyzed the first 20 consecutive infants undergoing pyloromyotomy according to WeberRamstedt with single shot epidural anaesthesia. Pertinent patient data are illustrated in Table

1. The relevant blood gas values after admission in the hospital and before surgery are illustrated in Table 2.

Anaesthesia management via sedation (details are described in Table 2) and ultrasound guided single shot thoracic epidural blockade was successful in all infants. Thus, no rapid sequence intubation as described in the methods section and reversal of neuromuscular blockade was required.

As expected, median (range) decrease in heart rate after administration of $0.75 \mathrm{ml} \mathrm{kg}^{-1}$ ropivacaine $0.475 \%$ was $18 \%(5-30 \%)$ and remained stable on post-epidural lower level during the entire surgical procedure (Figure 3). Oxygen saturation remained stable between 97 and $100 \%$ in all cases throughout the entire anaesthesia and surgical procedure, except in one case where $\mathrm{SpO}_{2}$ decreased to $92 \% 10$ min after epidural anaesthesia. Treatment of this short episode of decrease in $\mathrm{SpO}_{2}$ was performed by assisted positive pressure ventilation via face mask.

All OPS scores remained $<5$ and therefore no child received additional systemic pain therapy in the recovery room. The examination of the epidural puncture site 24 hours postoperatively was uneventful in all cases. 


\section{Discussion}

This consecutive case series describes a novel anaesthesia management for pyloromyotomy in infants suffering from HPS. Ultrasound guided single shot thoracic epidural anaesthesia under sedation and spontaneous respiration has been a useful technique in this retrospective series of infants for pyloromyotomy. In this particular retrospective study of 20 cases, airway manipulation and mechanical ventilation could be avoided.

Pyloromyotomy is usually performed under general anaesthesia, thus requiring tracheal intubation and rapid sequence induction of general anaesthesia (5). The use of regional anaesthesia techniques depends on the exact site of surgery. As most surgical techniques for pyloromyotomy require a supraumbilical skin incision, spinal and caudal blockade seem inadequate. Kachko et al. suggest spinal anaesthesia only for low abdominal procedures (8), whereas Somri et al. and Jetzek-Zader et al. describe high spinal blockade with bupivacaine $0.5 \%\left(0.8 \mathrm{mg} \mathrm{kg}^{-1}\right.$ and $1.3 \mathrm{mg} \mathrm{kg}^{-1}$, respectively) as possible regional anaesthetic technique and as an alternative to general anaesthesia for pyloromyotomy $(9,18)$. Moyao-Garcia et al. suggest caudal blockade with bupivacaine $0.25 \%$ and a volume of $1.6 \mathrm{ml}$ for pyloromyotomy and describe a success rate of $96 \%$ (11). In spite of all these encouraging reports, our clinical experience was based on the observation that caudal blockade is insufficient for WeberRamstedt repair of HPS due to a required cranial analgesic level between T4 and 6. Preliminary and unpublished data show that only in the minority of cases a spread above T12 can be achieved via the caudal approach, even with a volume of local anaesthetic of 1.5 $\mathrm{mg} \mathrm{kg}^{-1}$. On the other hand, spinal anaesthesia for pyloromyotomy may cause uncontrolled high blockade and subsequent respiratory insufficiency.

During the past 10 years our study group acquired a substantial experience in the area of central $(12,13,19)$ regional anaesthetic techniques with ultrasound guidance. In the light of 
the findings above and our own significant experience with epidural anaesthesia in infants, we considered ultrasound guided single shot thoracic epidural blockade with sedation as a possible alternative to other techniques. The analysis of our first consecutive cases showed that thoracic epidural blockade under ultrasound guidance is a useful anaesthesia method for Weber-Ramstedt pyloromyotomy. Once the epidural space is identified via a combination of LOR and direct visualization, the spread of local anaesthetic can be directly observed.

We administered from the first case ropivacaine $0.475 \%$ (1:1 mixture of ropivacaine $0.75 \%$ and $0.2 \%$ ) with a volume of $0.75 \mathrm{ml} \mathrm{kg}^{-1}$ and observed an adequate cranial spread of local anaesthetic with no alterations in ventilation. This volume and concentration may be considered as relatively large, but pharmacokinetics of epidural ropivacaine in infants is insufficiently described. Anyway, systemic resorption of ropivacaine from the epidural space seems to be slower as compared with bupivacaine, thus increasing the safety of epidural ropivacaine in infants (20). Due to the fact that no data existed regarding optimal volume and concentration of local anaesthetic for this particular indication, we have been prepared for alterations in volume and concentration of local anaesthetic. Fortunately the initial choice of volume and concentration of local anaesthetic was effective and seems to be safe regarding spontaneous ventilation. Anyway, further studies should investigate lower concentrations of epidural ropivacaine for treatment of HPS.

It is important to highlight that the described technique requires particular training and handskills. Anyway, paediatric anaesthesia nowadays is a highly specialized profession and therefore children, independent of the severity of their disease, should be treated only by dedicated paediatric anaesthetists and surgeons (21). In experienced hands, ultrasound guided thoracic epidural anaesthesia may be considered as safe technique. Careful miscellaneous management (sedation under maintenance of spontaneous respiration, suctioning of the stomach, etc.) is equally important for the safe and successful management of these cases. 
The presented technique is only possible when open surgical procedures are performed.

Nowadays laparoscopic procedures become more and more popular, which is also the case for pyloromyotomy. Two recent meta-analyses are available comparing open versus laparoscopic pyloromyotomy. Sola et al. identified 6 studies with 303 patients sufficient to be included in a meta-analysis and found slight advantages for laparoscopic procedures in terms of shorter time to full feeding, shorter postoperative length of stay and a reduced rate of total complications (22). Conversely, Hall et al. published a meta-analysis based on 8 studies and 595 patients and found fewer complications and a higher efficacy when open pyloromyotomy was performed (23). None of these publications consider the implications of anaesthesia management on morbidity. Anyway, from todays point of view laparoscopic pyloromyotomy shows no clear advantages compared with the open technique. Moreover, avoidance of tracheal intubation, subsequent ventilation and possible postoperative respiratory depression when thoracic epidural anaesthesia is performed may serve as another argument for open pyloromyotomy.

A major advantage of the reported technique is the fact that it can be used for all surgical open approaches. Despite not investigated in this retrospective analysis, paraumbilical procedures can be also treated with epidural single shot blockade. Another possible advantage is the operation time saving effect of pure regional anaesthesia based methods as compared with general anaesthesia. Kachko et al. reported about the time saving effects of spinal anaesthesia for HPS (24). Despite we did not exactly evaluate the anaesthesia control time in our retrospective analyses, is seems to be obvious that the avoidance of emerge from general anaesthesia is directly associated with faster procedural times.

The clear limitation of this report is that it is just a descriptive consecutive case series. However, from our point of view descriptive reports are useful and sufficient to describe anaesthetic techniques for particular surgical procedures. Another limitation is that we were 
not able to evaluate OPS scores on the ward and therefore no statement regarding pain and behaviour after transfer from the recovery room can be provided.

In summary, thoracic epidural anaesthesia under sedation for pyloromyotomy has been a useful technique in this retrospective series of infants suffering from HPS. We did not observe any haemodynamic or respiratory complications in this consecutive series of 20 infants undergoing Weber-Ramstedt pyloromyotomy. Undisturbed surgery was possible in all cases. 


\section{Tables}

Table 1. Pertinent patient data. Values are median (min-max) except where indicated otherwise

\section{Patient data}

Gender (m/f)

$17 / 3$

Age (months)

$1.7(1.5-4.0)$

Weight $(\mathrm{g})$

$3895(1800-5000)$

Duration of surgery (min)

$25(10-40)$

Table 2. Relevant blood gas values, sedation details and volume of local anaesthetic for epidural single shot blockade. Values are mean (min-max or $S D$ )

$\mathrm{pH}$ at admission

$7.52(7.41-7.67)$

$\mathrm{HCO}_{3}^{-}\left(\mathrm{mmol} \cdot \mathrm{l}^{-1}\right)$ at admission

$30.9(21.1-44.2)$

$\mathrm{pH}$ preoperative

$7.40(7.36-7.49)$

$\mathrm{HCO}_{3}^{-}\left(\mathrm{mmol} \cdot 1^{-1}\right)$ preoperative

$25.3(21.6-28.0)$ 
Sedation details

Total propofol (mg)

$13.3(7.8)$

Nalbuphine (mg)

$0.6(0.2)$

Local anaesthetic volume

$2.9(1.4-3.8)$ 


\section{Figure legends}

Figure 1

Position of the ultrasound probe relative to the Tuohy epidural needle

Figure 2

Ultrasound observation of the spread of local anaesthetic inside the epidural space. LA = local anaesthetic inside the epidural space; $\mathrm{DM}=$ dura mater; $\mathrm{CM}=$ conus medularis

Figure 3

Heart rate of all infants before and after single shot thoracic epidural blockade. Bold line = mean heart rate 


\section{References}

1 Nielsen JP, Haahr P, Haahr J. Infantile hypertrophic pyloric stenosis. Decreasing incidence. Dan Med Bull 2000; 47: 223-225.

2 O'Donoghue JM, Connolly KD, Gallagher MM, et al. The increasing incidence of infantile hypertrophic pyloric stenosis. Ir J Med Sci 1993; 162: 175-176.

3 Applegate MS, Druschel CM. The epidemiology of infantile hypertrophic pyloric stenosis in New York State, 1983 to 1990. Arch Pediatr Adolesc Med 1995; 149: 1123-1129.

$4 \quad$ Wang J, Waller DK, Hwang LY, et al. Prevalence of infantile hypertrophic pyloric stenosis in Texas, 1999-2002. Birth Defects Res A Clin Mol Teratol 2008; 82: 763-767.

$5 \quad$ Bissonnette B, Sullivan PJ. Pyloric stenosis. Can J Anaesth 1991; 38: 668-676.

6 Fuzaylov G, Kim AH, Rosow CE. Delayed awakening from general anesthesia in a hypovolemic infant. Paediatr Anaesth 2005; 15: 435-436.

7 Frei FJ, Erb T, Jonmarker C, et al. Hypertrophe Pylorusstenose. In: Frei, ed. Kinderanästhesie. Berlin, Heidelberg, New York: Springer, 2004:80-82.

8 Kachko L, Simhi E, Tzeitlin E, et al. Spinal anesthesia in neonates and infants - a single-center experience of 505 cases. Paediatr Anaesth 2007; 17: 647-653.

9 Somri M, Gaitini LA, Vaida SJ, et al. The effectiveness and safety of spinal anaesthesia in the pyloromyotomy procedure. Paediatr Anaesth 2003; 13: 32-37.

10 Busto Aguirreurreta N, Cia Armendariz ML, Carrascosa Moreno S, et al. [Caudal epidural anesthesia in pyloromyotomy in infants: our experience]. Cir Pediatr 2000; 13: 153155.

11 Moyao-Garcia D, Garza-Leyva M, Velazquez-Armenta EY, et al. Caudal block with 4 mg x kg-1 (1.6 ml x kg-1) of bupivacaine $0.25 \%$ in children undergoing surgical correction of congenital pyloric stenosis. Paediatr Anaesth 2002; 12: 404-410.

12 Willschke H, Bosenberg A, Marhofer P, et al. Epidural catheter placement in neonates: sonoanatomy and feasibility of ultrasonographic guidance in term and preterm neonates. Reg Anesth Pain Med 2007; 32: 34-40.

13 Willschke H, Marhofer P, Bosenberg A, et al. Epidural catheter placement in children: comparing a novel approach using ultrasound guidance and a standard loss-of-resistance technique. Br J Anaesth 2006; 97: 200-207.

14 Brenner L, Kettner SC, Marhofer P, et al. Caudal anaesthesia under sedation: a prospective analysis of 512 infants and children. Br J Anaesth 2010; 104: 751-755.

15 Machata AM, Willschke H, Kabon B, et al. Propofol-based sedation regimen for infants and children undergoing ambulatory magnetic resonance imaging. Br J Anaesth 2008; 101: $239-243$. 
16 Pfeifer K. [Results of the Weber-Ramstedt operation in infantile pyloristenosis.]. Med Klin 1950; 45: 1140-1141.

17 Garza JJ, Morash D, Dzakovic A, et al. Ad libitum feeding decreases hospital stay for neonates after pyloromyotomy. J Pediatr Surg 2002; 37: 493-495.

18 Jetzek-Zader M. High spinal anaesthesia in a formerly preterm infant undergoing pyloromyotomy. Paediatr Anaesth 2001; 11: 507.

19 Marhofer P, Bosenberg A, Sitzwohl C, et al. Pilot study of neuraxial imaging by ultrasound in infants and children. Paediatr Anaesth 2005; 15: 671-676.

20 Karmakar MK, Aun CS, Wong EL, et al. Ropivacaine undergoes slower systemic absorption from the caudal epidural space in children than bupivacaine. Anesth Analg 2002; 94: 259-265, table of contents.

21 Allan C. Determinants of good outcome in pyloric stenosis. J Paediatr Child Health 2006; 42: 86-88.

22 Sola JE, Neville HL. Laparoscopic vs open pyloromyotomy: a systematic review and meta-analysis. J Pediatr Surg 2009; 44: 1631-1637.

23 Hall NJ, Van Der Zee J, Tan HL, et al. Meta-analysis of laparoscopic versus open pyloromyotomy. Ann Surg 2004; 240: 774-778.

24 Kachko L, Simhi E, Freud E, et al. Impact of spinal anesthesia for open pyloromyotomy on operating room time. J Pediatr Surg 2009; 44: 1942-1946. 
Position of the ultrasound probe relative to the Tuohy epidural needle $1236 \times 824 \mathrm{~mm}(72 \times 72$ DPI $)$ 
Ultrasound observation of the spread of local anaesthetic inside the epidural space. LA = local anaesthetic inside the epidural space; $\mathrm{DM}=$ dura mater; $\mathrm{CM}=$ conus medularis $133 \times 91 \mathrm{~mm}(96 \times 96 \mathrm{DPI})$ 


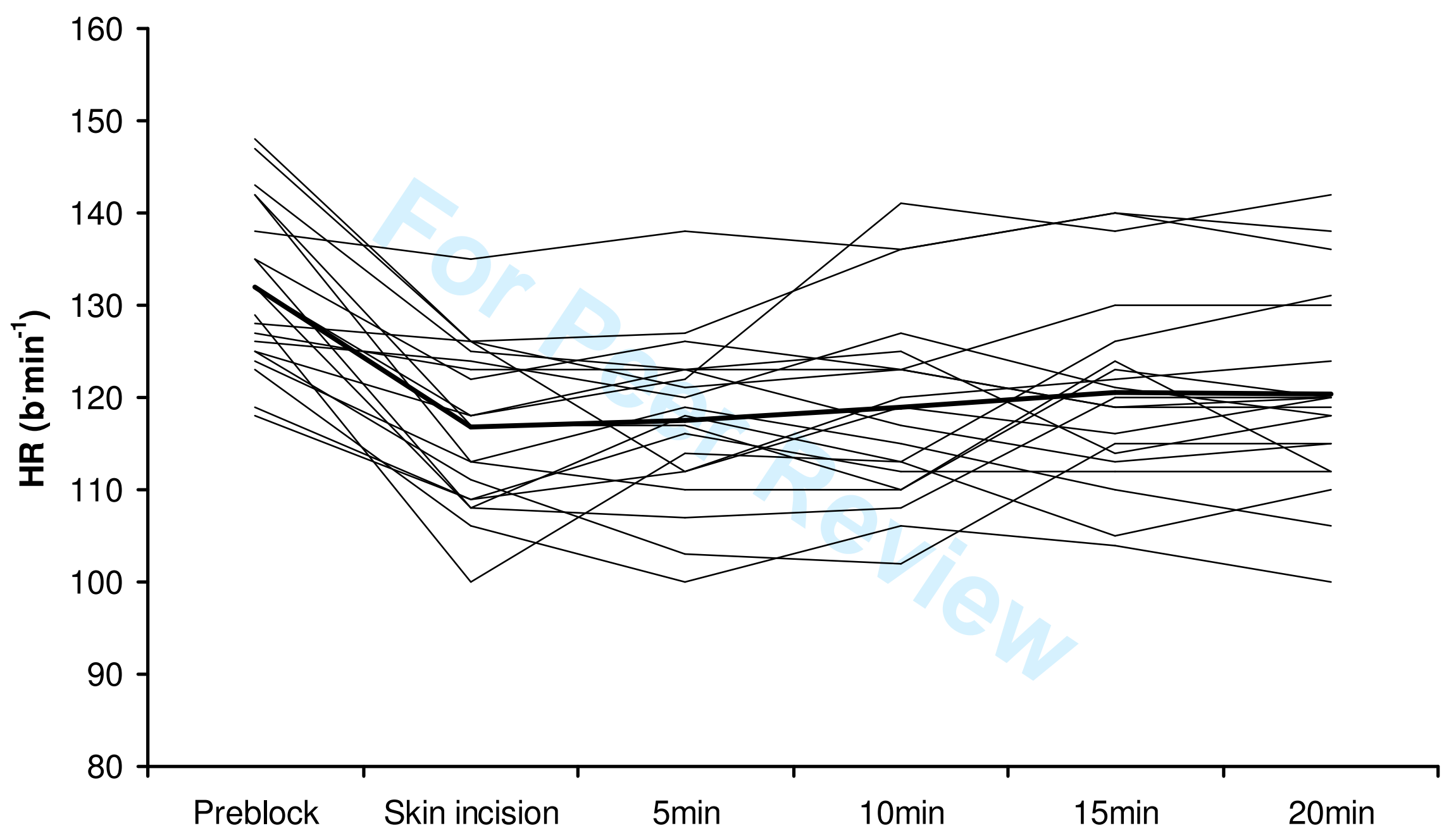

